\title{
The SARS-CoV-2 receptor, ACE-2, is expressed on many different cell types: implications for ACE-inhibitor- and angiotensin II receptor blocker-based cardiovascular therapies: comment
}

\author{
Harald De Cauwer ${ }^{1,2}$ (D)
}

Received: 3 June 2020 / Accepted: 8 June 2020 / Published online: 20 June 2020

(c) Società Italiana di Medicina Interna (SIMI) 2020

Dear editor,

Albini et al. describe the role of the angiotensin-converting enzyme (ACE)-2-receptor in COVID-19: the receptor acts as a viral receptor and is expressed on the surface of several pulmonary and extra-pulmonary cell types. Because chromosome $\mathrm{X}$ is harbouring the gene coding for ACE-2, this could be one of the possible explanations of why mortality of COVID-19 in female patients is lower. The authors pose several questions on the role of this receptor in COVID19 that need clarification [1].

SARS-CoV-2 indeed needs the ACE-2-receptor for cell entry, but important as well, and even more, is the role of the transmembrane serine protease TMPRSS2 which is working in close contact with the ACE-receptor [1, 2].

This protease has been linked to cell entry and infection severity in Influenza, MERS, SARS-CoV-1, metapneumovirus, and SARS-CoV-2. It also reduces humoral immunity and as such influences disease severity.

The gene for the expression of TMPRSS2 is located on chromosome 21, as well as other genes for transmembrane proteases [3].

The modulation of its expression by sex steroids could contribute to the male predominance of severe infections [4].

So two different pathways can explain excess morbidity and mortality in males. The same accounts for diabetes, another risk factor for COVID-19-mortality: there appears to be also a link with both ACE-2-receptor and TMPRSS2.

Maybe, a specific group of patients can add to reveal more of the role and effect of these binding sites in viral disease course: Down patients.

Harald De Cauwer

harald.decauwer@ziekenhuisgeel.be

1 Department of Neurology, Dimpna Regional Hospital, JB Stessenstraat 2, 2440 Geel, Belgium

2 Faculty of Medicine and Health Sciences, University of Antwerp, Wilrijk, Belgium
Patients with Down Syndrome (Trisomy 21) are known to have more severe disease course when infected by the aforementioned pathogens, including SARS-CoV-2: patients probably fall ill more frequently, have higher morbidity and excess mortality, mostly due to experiencing more severe acute respiratory distress syndrome [5].

It is assumed that overexpression of chromosome 21 genes, as a result of their presence in an extra copy, causes the Down Syndrome phenotype. In this case, over-expression of TMPRSS2 might explain why Down patients are more prone to viral diseases (Influenza, SARS-CoV-1, Metapneumovirus, MERS, and SARS-CoV-2) that use ACE2-receptor/TMPRSS2 for cell binding/cell entry. They might get more cells infected because of more protease activity and thus more easily cell entry of the viral pathogens.

Testing the effect of available TMPRSS2 inhibitors blocking entry are warranted, besides testing ACE-receptor blockers. Patients getting ill from the second wave of COVID-19 need a better treatment regimen. Now is the time to study the candidate molecules in order to be better prepared for the second wave and to offer patients a better objective.

\section{Compliance with ethical standards}

Conflict of interest The author declares that this "Letter to the editor" article was written in the absence of any commercial or financial relationships that could be construed as a potential conflict of interest.

Statement of human and animal rights This article does not contain any studies with human participants or animals performed by any of the authors.

Informed consent Informed consent was not required for this type of study which represents an opinion (letter to the editor) paper. 


\section{References}

1. Albini A, Di Guardo G, McClain Noonan D, Lombardo M (2020) The SARS-CoV-2 receptor, ACE-2, is expressed on many different cell types: implications for ACE-inhibitor- and angiotensin II receptor blocker-based cardiovascular therapies. Intern Emerg Med 19:1-8. https://doi.org/10.1007/s11739-020-02364-6

2. Hoffmann H, Kleine-Weber H, Schroeder S, Krüger N, Herrler T, Erichsen S, Schiergens TS, Herrler G, Wu NH, Nitsche A, Müller MA, Drosten C, Pöhlmann S (2020) Cell 181(2):271-280.e8. https ://doi.org/10.1016/j.cell.2020.02.052

3. Gardiner K, Muriel Davisson M (2000) The sequence of human chromosome 21 and implications for research into Down syndrome. Genome Biol 1(2):reviews0002.1-reviews0002.9
4. Stopsack KH, Mucci LA, Antonarakis ES, Nelson PS, Kantoff PW (2020) TMPRSS2 and COVID-19: serendipity or opportunity for intervention? Cancer Discov. https://doi.org/10.1158/2159-8290. CD-20-0451

5. De Cauwer H, Spaepen A (2020) Are patients with Down syndrome vulnerable to life-threatening COVID-19? Acta Neurol Belg 22:1-3. https://doi.org/10.1007/s13760-020-01373-8

Publisher's Note Springer Nature remains neutral with regard to jurisdictional claims in published maps and institutional affiliations. 